\title{
Role of Oral Appliances in Sleep Apnea
}

\author{
Smriti Jagdhari Golhar* \\ Department of Oral Medicine \& Radiology, VSPM'S Dental College \& Research Center, India
}

*Corresponding author: Smriti Jagdhari Golhar, Assistant Professor, Department of Oral Medicine \& Radiology, VSPM'S Dental College \& Research Center, C/O Dr. Anil Golhar, 256 Ramdaspeth, Nagpur, Maharashtra, India

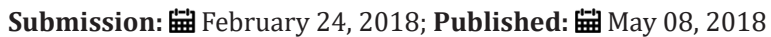

\section{Editorial}

Sleep apnea (or sleep apnoea in British English) is a sleep disorder characterized by abnormal pauses in breathing or instances of abnormally low breathing, during sleep. There are different types of apnea, Obstructive sleep apnea, Central sleep apnea and mixed. Obstructive sleep apnea (OSA) is the most common category of sleep-disordered breathing. Obstructive sleep apnea syndrome (OSAS) is characterized by recurrent episodes of cessation of respiratory airflow during sleep due to collapse of the upper airway (UA) at the level of the pharynx [1].

There symptoms are loud snoring, awakening with a dry mouth or sore throat, morning headache, excessive daytime sleepiness (hypersomnia), attention problems, irritability. The two most common therapies used to treat obstructive sleep apnea (OSA) are: (1) continuous positive airway pressure (CPAP), and (2) oral appliances. Oral appliances categorized as, soft palate lifters (SPL), tongue retaining devices (TRD), and mandibular advancement appliances or splints (MAA or MAS). MAS are used more commonly than other oral appliance [2].

A TRD uses a pliable silicon bulb fitted over a protruded tongue and held in place by suction, supported additionally by the teeth and soft tissues. This forward posture of tongue prevents it from collapsing back into the oropharyngeal airway and maintains a patent air passage at the level of site of airway collapse. MAA are designed to reposition the mandible forward and support this protrusive posture during sleep [3].

This approach of action is most likely involves a structural change to the pharynx enlarging the retroglossal airway via forward displacement of the tongue or lateral airway expansion. Several studies had been done to prove the efficiency of these appliances, in treatment both snoring and OSA [4]. According to Kushida et al. [5], American Academy of Sleep Medicine suggested OA therapy as a first-line treatment in patients with mild to moderate OSA and for patients with more severe OSA who fail treatment attempts with CPAP therapy. Every treatment modality has its pros and cons. Excessive salivation, mouth, and teeth discomfort are the most common side effects reported with MAA. Treatment decisions should be carefully planned with assessment of multiple factors in each case of OSA because every patient is different sign and symptom. Sleep physicians should understand the importance of multidisciplinary approach of dentist in this field and gives requires cooperation to treat the condition.

\section{References}

1. Pépin JL (1987) Obstructive sleep apnea syndrome: hooked appearance of the soft palate in awake patients-cephalometric and CT findings. American Journal of Orthodontics and Dentofacial Orthopedics 91(5): 414-426.

2. Almeida FR, Bansback N (2013) Long-term effectiveness of oral appliance versus CPAP therapy and the emerging importance of understanding patient preferences. Sleep 36(9): 1271-1272.

3. Cistulli P, Gotsopoulos H, Marklund M, Lowe A (2004) Treatment of snoring and obstructive sleep apnea with mandibular repositioning appliances. Sleep Med Rev 8(6): 443-457.

4. Tsuda H, Wada N, Ando S (2017) Practical considerations for effective oral appliance use in the treatment of obstructive sleep apnea: a clinical review. Sleep Science and Practice 1: 12.

5. Kushida CA, Morgenthaler TI, Littner MR, Alessi CA, Bailey D, et al. (2006) Practice parameters for the treatment of snoring and Obstructive Sleep Apnea with oral appliances: an update for 2005. Sleep 29(2): 240-243. 
Creative Commons Attribution 4.0 International License

For possible submissions Click Here

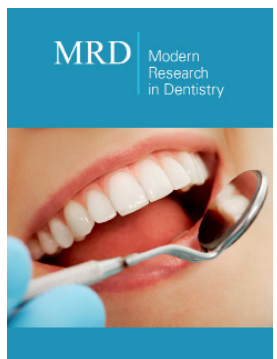

\section{Modern Research in Dentistry}

\section{Benefits of Publishing with us}

- High-level peer review and editorial services

- Freely accessible online immediately upon publication

- Authors retain the copyright to their work

- Licensing it under a Creative Commons license

- Visibility through different online platforms 